\title{
Superfícies fotocatalíticas de titânia em substratos cerâmicos. Parte II: substratos, processos de deposição e tratamento térmico
}

\author{
(Photocatalytic surfaces of titania on ceramic substrates. \\ Part II: substrates, deposition and heat treating processes) \\ J. Feltrin ${ }^{1,2}$, M. N. Sartor ${ }^{1}$, A. De Noni Jr ${ }^{2,3}$, A. M. Bernardin ${ }^{3}$ D. Hotza ${ }^{1}$, J. A. Labrincha ${ }^{4}$ \\ ${ }^{1}$ Programa de Pós-Graduação em Ciência e Engenharia dos Materiais, Universidade Federal de Santa Catarina, \\ Florianópolis, SC 88040-900 \\ ${ }^{2}$ Instituto Maximiliano Gaidzinski, R. Edson Gaidzinski 352, Cocal do Sul, SC 88845-000 \\ ${ }^{3}$ Universidade do Extremo Sul Catarinense, Av. Universitária 1105, Bairro Universitário, Criciúma, SC 88806-000 \\ ${ }^{4}$ Departamento de Engenharia Cerâmica e do Vidro, Universidade de Aveiro, Aveiro, Portugal 3810-193
}

\begin{abstract}
Resumo
Este trabalho corresponde à segunda parte da revisão das superfícies fotocatalíticas de titânia em substratos cerâmicos. Nesta parte, são descritos os principais fatores que influenciam na obtenção da fase anatase como: substrato, processos de deposição e tratamento térmico. Nos substratos que apresentam superfícies ásperas há uma maior eficiência fotocatalítica devido a sua maior área de contato. Os processos de deposição mais comumente utilizados em superfícies cerâmicas são: magnetron sputtering, dip coating, spin coating, serigrafia plana, pulverização, incavografia e impressão digital. Com relação ao tratamento térmico do dióxido de titânio, em todas as temperaturas e pressões a fase rutilo é a mais estável. A fase anatase é metaestável atingindo a estabilidade apenas em temperaturas baixas. A transformação de fase anatase para rutilo é gradual não apresentando uma temperatura definida.
\end{abstract}

Palavras-chave: dióxido de titânio, superfícies cerâmicas, estabilidade de fase.

\section{Abstract}

This work corresponds to the second part of the review of photocatalytic titania surface on ceramic substrates. In this review, the main factors that influence the production of anatase as the influence of substrate, deposition and heat treatment processes. In substrates with rough surfaces, higher photocatalytic efficiency is reported due to the higher contact area. Deposition processes commonly used in ceramic surfaces are: magnetron sputtering, dip coating, spin coating, screen printing, silk screen, powder spraying, rotocolor and digital printing. After heat treating the titanium dioxide, it can be seen that at all temperatures and pressures rutile is more stable as anatase. The later is metastable achieving stability only at low temperatures. The transformation from anatase to rutile occurs gradually in a broad temperature range.

Keywords: titanium dioxide, ceramic surfaces, phase stability.

\section{INTRODUÇÃO}

A fotocatálise com dióxido de titânio tem sido utilizada para uma grande variedade de aplicações, que se relacionam em particular com decomposição de compostos orgânicos tóxicos produzindo moléculas simples como o dióxido de carbono e água, destruição de poluentes da água contaminada, do ar, bactérias e células cancerígenas [1,2].

Em geral, a forma polimórfica anatase é preferida devido à sua alta atividade fotocatalítica. No entanto, essa fase não é estável a altas temperaturas e sua aplicação em produtos cerâmicos é limitada. Vários aspectos estão sendo estudados e a eficiência fotocatalítica é dependente de parâmetros relacionados com a natureza do substrato, método de deposição e tratamento térmico.

\section{Substratos}

O dióxido de titânio em sua forma anatase não é estável a altas temperaturas, transformando-se irreversivelmente em rutilo, fase pouco fotoativa. Inibir esta transformação de fase é importante para a aplicação em cerâmicas tradicionais que utilizam temperaturas altas (acima de $800^{\circ} \mathrm{C}$ ). A transformação de fase $\mathrm{A} \rightarrow \mathrm{R}$ não tem uma temperatura definida, é gradual $\mathrm{e}$ dependente de numerosos parâmetros relacionados com a natureza do material, tratamento térmico e método de medição. Pode-se inibir essa transformação de fase com a adição de um dopante ou a presença de impurezas no anatase. Da mesma forma, deve-se analisar a composição do substrato e a interação deste com a camada depositada de titânia, pois há uma grande influência no tipo de fase resultante [3]. A Tabela I relaciona 
Tabela I - Relação de diferentes naturezas de substrato na estabilidade da fase anatase.

[Table I - Relation of different kinds of substrate on stability of anatase.]

\begin{tabular}{|c|c|c|c|}
\hline Natureza do Substrato & $\begin{array}{l}\text { Técnica de } \\
\text { aplicação }\end{array}$ & Resultados na estabilidade da fase & Ref. \\
\hline $\begin{array}{l}\text { Cerâmica com } \\
\text { esmalte tipo } 01\left(\mathrm{Na}_{2} \mathrm{O} \text { e } \mathrm{K}_{2} \mathrm{O}\right) \\
\text { Cerâmica com } \\
\text { esmalte tipo } 02\left(\mathrm{Na}_{2} \mathrm{O} \text { e } \mathrm{K}_{2} \mathrm{O}\right) \\
\text { Cerâmica com } \\
\text { esmalte tipo } 03\left(\mathrm{Na}_{2} \mathrm{O} \text { e } \mathrm{K}_{2} \mathrm{O}\right) \\
\text { Coríndon (inerte) }\end{array}$ & Dip coating & $\begin{array}{l}\text { A estabilidade térmica do filme de anatase é fortemente } \\
\text { influenciada pelos cátions presentes no esmalte e na } \\
\text { capacidade destes em gerar vacâncias de oxigênio } \\
\left.\text { induzindo a formação de rutilo (em } 1080^{\circ} \mathrm{C}\right) \text {. Substratos } \\
\text { inertes e altamente cristalinos, como coríndon não } \\
\text { apresentam cátions livres e, portanto apresentam maior } \\
\text { estabilidade térmica. Foi observada a transformação } \\
\text { inicial de } \mathrm{A} \rightarrow \mathrm{R} \text { entre } 1000 \text { e } 1200^{\circ} \mathrm{C} \text {. }\end{array}$ & [29] \\
\hline $\begin{array}{l}\text { Cerâmica com } \\
\text { esmalte branco brilhante }\left(\mathrm{em}_{\left.\mathrm{ZrO}_{2}\right)}\right.\end{array}$ & Serigrafia & $\begin{array}{l}\text { O recozimento ocorreu a } 790{ }^{\circ} \mathrm{C} \text {. A capacidade de } \\
\text { degradação fotocatalítica na amostra com cristais de } \\
\text { zirconita melhora em } 33 \% \text { a atividade fotocatalítica } \\
\text { comparando com o vidrado base transparente. O } \\
\text { aumento da frita de } \mathrm{ZrO}_{2} \text { (até } 12,5 \% \text { ) na formulação de } \\
\text { esmalte melhora a atividade fotocatalítica em relação ao } \\
\text { vidrado transparente normal, a composição ótima é de } \\
4 \% \text { de anatase. }\end{array}$ & {$[30]$} \\
\hline Vidro (flotado) & $\begin{array}{l}\text { Magnetron } \\
\text { sputtering }\end{array}$ & $\begin{array}{l}\text { As amostras dos filmes de } \mathrm{TiO}_{2} \text { foram queimadas a } \\
\text { temperaturas de } 350,400,450,500 \text { e } 550^{\circ} \mathrm{C} \text { com } \\
\text { camadas de titânia. Todas apresentaram atividade } \\
\text { fotocatalítica. A refletância dos filmes sobre cerâmica é } \\
\text { maior que as dos filmes sobre vidro, pois em materiais } \\
\text { transparentes como o vidro ocorre transmitância, e } \\
\text { também porque a refletância da cerâmica branca é muito } \\
\text { maior que a do vidro. }\end{array}$ & {$[7]$} \\
\hline $\begin{array}{l}\text { Vidro } \\
\text { Safira } \\
\text { Silício }\end{array}$ & Pintura & $\begin{array}{l}\text { Os materiais foram recozidos a temperatura de } 447^{\circ} \mathrm{C} \text { e } \\
\text { apresentam a fase anatase nos filmes aplicados nos três } \\
\text { substratos. }\end{array}$ & {$[31]$} \\
\hline Cerâmica áspero & Pulverização & $\begin{array}{l}\text { Os filmes foram tratados a } 840{ }^{\circ} \mathrm{C} \text { e obteve-se } 93 \% \text { de } \\
\text { anatase. A quantidade de azul de metileno adsorvido no } \\
\text { substrato áspero é o dobro em relação ao liso e, portanto } \\
\text { ocorre maior degradação fotocatalítica naquele. A taxa } \\
\text { de degradação é } 90 \% \text { do azul de metileno nas superfícies } \\
\text { lisas e } 94 \% \text { nas superfícies ásperas. }\end{array}$ & {$[32]$} \\
\hline $\begin{array}{l}\text { Cerâmica com esmalte de laboratório } \\
\text { mate (fase diopsídio) - 3A } \\
\text { Cerâmica com esmalte mate } \\
\text { (fase zircão) - M } \\
\text { Cerâmica com esmalte brilhante } \\
\text { (fase zircão) - K }\end{array}$ & Dip coating & $\begin{array}{l}\text { Foi analisada a rugosidade superficial das peças após } \\
\text { recozimento a } 500{ }^{\circ} \mathrm{C}: 3 \mathrm{~A}, \mathrm{M}, \mathrm{K} \text { (rugosidades } 0,38, \\
0,38,0,09 \mu \mathrm{m} \text { ). Após a exposição UV, a taxa de reação } \\
\text { fotocatalítica aumenta com a rugosidade em função } \\
\text { do aumento da área de superfície disponível para } \\
\text { decomposição. }\end{array}$ & {$[4]$} \\
\hline $\begin{array}{l}\text { Cerâmica com esmalte de laboratório } \\
\text { mate (fase diopsídio) - 3A } \\
\text { Cerâmica com esmalte mate } \\
\text { (fase zircão) - M }\end{array}$ & Dip c & $\begin{array}{l}\text { Revestimentos de } \mathrm{ZrO}_{2} \text { foram recozidos a } 600{ }^{\circ} \mathrm{C} \text { e } \\
\mathrm{TiO}_{2} \text { a } 500{ }^{\circ} \mathrm{C} \text {. Esmalte mate com recobrimento de } \mathrm{TiO}_{2} \\
\text { apresenta maior facilidade de limpeza, enquanto que no } \\
\text { esmalte brilhante o efeito não é tão pronunciado. Nos } \\
\text { revestimentos de } \mathrm{ZrO}_{2} \text { há maior aderência de partículas } \\
\text { orgânicas e inorgânicas. Introduzindo-se zircônia, a } \\
\text { fim de aumentar a resistência mecânica e química do } \\
\text { revestimento de } \mathrm{TiO}_{2} \text {, pode-se afetar adversamente a } \\
\text { capacidade de auto-limpeza do revestimento. }\end{array}$ & {$[33]$} \\
\hline
\end{tabular}


Continuação

\begin{tabular}{ccc}
\hline Natureza do Substrato & $\begin{array}{c}\text { Técnica de } \\
\text { aplicação }\end{array}$ & Resultados na estabilidade da fase \\
\hline
\end{tabular}

Silício (Si) monocristalino monoporosa)

Pulverização

Magnetron

sputtering

\begin{abstract}
Sílica $\left(\mathrm{SiO}_{2}\right)$ fundida
\end{abstract}

\begin{tabular}{cll}
\hline $\begin{array}{c}\text { Cerâmica (azulejos de } \\
\text { monoporosa) }\end{array}$ & Pulverização & $\begin{array}{l}\text { As titânias comerciais P25, Kronos, Quimiamel CH e CR-826 } \\
\text { foram aplicadas e tratadas termicamente até } \\
1200{ }^{\circ} \mathrm{C} \text {. A titânia Kronos apresenta maior fase anatase após } \\
\text { tratamento térmico. }\end{array}$ \\
\hline $\begin{array}{c}\text { Cerâmica (azulejos de } \\
\text { monoporosa) }\end{array}$ & Serigrafia & $\begin{array}{l}\text { A titânia comercial Kronos e o óxido de zinco (ZnO) foram } \\
\text { aplicados e tratados termicamente a } 850{ }^{\circ} \mathrm{C} \text {. A titânia Kronos em } \\
\text { comparação ao ZnO, tem maior eficiência na descoloração do } \\
\text { laranjado II. }\end{array}$
\end{tabular}

No substrato de Si monocristalino, o rutilo dopado com $33 \%$ de $\mathrm{SiO}_{2}$ e tratado termicamente a $1000{ }^{\circ} \mathrm{C}$ com patamar de $1 \mathrm{~h}$ apresentou fase anatase.

No substrato de $\mathrm{SiO}_{2}$ fundida, o rutilo dopado com $33 \%$ de $\mathrm{SiO}_{2}$ e tratado termicamente a $1000{ }^{\circ} \mathrm{C}$ com patamar de $1 \mathrm{~h}$ apresentou fase amorfa.

A titânia obtida por duas rotas distintas foi aplicada e tratada termicamente a $500{ }^{\circ} \mathrm{C}$ com diferentes concentrações. Há maior

Vidro de borossilicato Dip coating eficiência fotocatalítica nos revestimentos quanto maior a quantidade de percursor aplicada e também quanto maior a espessura da aplicação.

\begin{tabular}{|c|c|c|c|}
\hline Vidro & Dip coating & $\begin{array}{l}\text { A titânia obtida pela rota sol gel foi aplicada e tratada } \\
\text { termicamente a } 450{ }^{\circ} \mathrm{C} \text {. Foram feitos testes de degradação } \\
\text { com as titânias comerciais em pó: P } 25 \text { E PC-500. A eficiência } \\
\text { fotocatalítica da titânia imobilizada no vidro é intermediária aos } \\
\text { pós P25 e PC-500. O P25 apresenta maior eficiência. }\end{array}$ & {$[37]$} \\
\hline Vidro de borosilicato & $\begin{array}{c}\text { Dip coating } \\
\text { e magnetron } \\
\text { sputtering }\end{array}$ & $\begin{array}{l}\text { Comparou-se: aplicação da titânia amorfa obtida via rota sol } \\
\text { por dip coating; aplicação de dispersão de P25 por dip coating } \\
\text { e titânia pura por magnetron sputtering. Esta última técnica } \\
\text { apresentou maior eficiência fotocatalítica por estar relacionada } \\
\text { com a criação de uma alta densidade na interface sólido-sólido e } \\
\text { ao impedimento da recombinação de cargas. }\end{array}$ & [38] \\
\hline Cerâmica (vidrado) & Spin coating & $\begin{array}{l}\text { A titânia modificada com fósforo, silício e zircônio foi obtida pela } \\
\text { combinação da rota sol gel com o processo hidrotermal. Cada } \\
\text { amostra foi aplicada e tratada termicamente a } 800^{\circ} \mathrm{C} \text {. Obteve-se } \\
\text { melhor eficiência fotocatalítica nas amostras dopadas. }\end{array}$ & [5] \\
\hline Vidro & Serigrafia & $\begin{array}{l}\text { Foi utilizado a titânia P25 e preparadas três pastas com } \\
\text { modificadores de superfície e solventes diferentes, aplicado e } \\
\text { tratado termicamente a } 450^{\circ} \mathrm{C} \text {. As composições apresentaram } \\
\text { diferentes superfícies disponíveis e o melhor resultado de } \\
\text { degradação está relacionado com aquela que apresentou maior } \\
\text { área superficial disponível para a fotodegradação . }\end{array}$ & [6] \\
\hline Quartzo e silício & Spin coating & $\begin{array}{l}\text { A titânia foi obtida pela rota sol gel. A amostra foi aplicada em } \\
\text { cada substrato e tratada termicamente variando de } 200 \text { a } 1000{ }^{\circ} \mathrm{C} \text {. } \\
\text { Obteve-se melhor eficiência fotocatalítica quando a fase anatase } \\
\text { está presente, ou seja, até } 800^{\circ} \mathrm{C} \text {. }\end{array}$ & [39] \\
\hline
\end{tabular}


estudos feitos comparando diferentes naturezas de substratos, técnicas de aplicação do filme de titânia e os resultados obtidos na estabilização da fase.

Ao se analisar os trabalhos desenvolvidos verifica-se que os melhores resultados para inibir a transformação de fase $\mathrm{A} \rightarrow \mathrm{R}$ estão nos substratos inertes como o de coríndon comparado aos substratos cerâmicos. Os íons de metais alcalinos e alcalino-terrosos presentes no esmalte favorecem a transição de fase devido à formação de vacâncias de oxigênio por substituição catiônica na interface esmaltetitânia $[2,4]$.

Para as análises nos substratos de cerâmica branca e de vidro os melhores resultados estão na cerâmica branca que devitrifica formando a fase cristalina zirconita $\left(\mathrm{ZrSiO}_{4}\right)$. O silicato de zircônio pode formar algum tipo de encapsulamento para os grãos de $\mathrm{TiO}_{2}$ sendo eficaz para reduzir o efeito dos metais alcalinos e alcalino-terrosos presentes na composição das fritas na transição de fase [5].

Características físicas da superfície como rugosidade/ aspereza dos produtos finais obtidos também tem sido relatadas como relevantes na decomposição fotocatalítica. Alguns trabalhos apontam diferenças significativas nos revestimentos finais com maior rugosidade, apresentando maior reação fotocatalítica em função do aumento da área superficial disponível, facilitando o contato das substâncias adsorvidas com os cristais existentes, consequentemente aumentando a eficiência fotocatalítica [4].

\section{Processos de deposição em superfícies cerâmicas}

As propriedades fotocatalíticas dos filmes de titânia dependem fortemente do processo de deposição [6]. As aplicações dos filmes podem ser feitas obtendo-se filmes finos e filmes grossos. Na maioria dos trabalhos em que se relata a variação da eficiência com a espessura, os filmes são submicrométricos. Nesses filmes, a quebra de cadeias de hidrocarbonetos aumenta com a espessura. $\mathrm{O}$ aumento da eficiência deve-se provavelmente a dois fatores [7]: aumento da espessura, proporcionando um aumento da quantidade de cristais de dióxido de titânio para participar da fotocatálise; aumento do número de cristais, que eleva o número de pares elétron-buraco gerado nos filmes de titânia. A fotocatálise melhora com a espessura até um determinado limite, a partir do qual se mantém quase constante. $\mathrm{O}$ valor limite de fotocatálise é alcançado em filmes mais espessos devido a [8]: formação de partículas de $\mathrm{TiO}_{2}$ no interior do filme, diminuindo o número de locais ativos na superfície; aumento da opacidade do filme e da difração da luz com o aumento da espessura do filme, o que diminui a passagem de luz através da espessura e, consequentemente, a geração de par elétron-buraco.

Filmes micrométricos sofrem alteração significativa na eficiência da fotocatálise devido ao aumento da espessura, apresentando um aumento da fotocatálise com o aumento da espessura do filme até o valor limite [7]. Os filmes finos podem ser depositados através de uma grande variedade de técnicas, que podem ser classificadas de acordo com

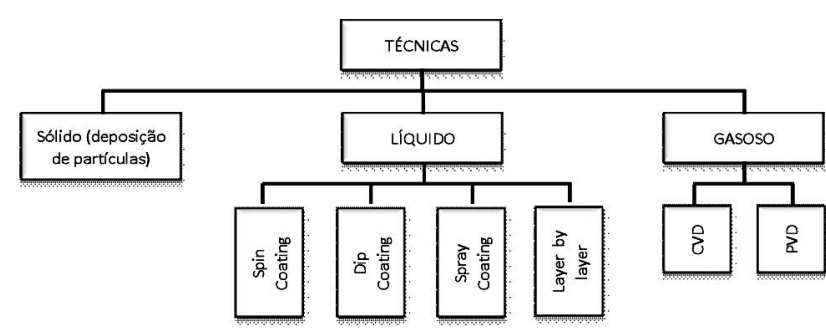

Figura 1: Diagrama dos principais métodos de obtenção de filmes. Fonte: Adaptado [9].

[Figure 1: Diagram of the major methods of obtaining films. Source: Adapted [9].]

a fase do meio contendo seu precursor. Na Fig. 1 estão relacionadas algumas técnicas de deposição de filmes a partir de precursores em fase sólida, líquida e gasosa [9].

Neste estudo serão descritas apenas aplicações de filmes finos sobre substratos cerâmicos através de magnetron sputtering com espessuras entre de 60 [3] a $890 \mathrm{~nm}$ [7]; dip coating, entre 80 a $115 \mathrm{~nm}$ [10] e menores $1 \mu \mathrm{m}$ [11]; spin coating com espessuras de 5 a $7 \mu \mathrm{m}$ [12]. Já para os filmes de maior espessura os mais utilizados são aplicados por serigrafia plana com espessuras médias de $12 \mu \mathrm{m}$ [13], $22 \mu \mathrm{m}, 38,5 \mu \mathrm{m}, 76,5 \mu \mathrm{m}$, aerógrafo com espessuras médias de $22 \mu \mathrm{m}, 38,5 \mu \mathrm{m}$ e 76,5 $\mu \mathrm{m}$ [14], impressão digital com espessuras até $70 \mu \mathrm{m}$ e incavografia com espessuras de até $100 \mu \mathrm{m}[15]$.

Obtenção de filmes finos - Deposição física ou química de vapor

Sputtering é um método de deposição a vácuo que permite o recobrimento de qualquer superfície sólida com uma grande variedade de material. É classificado como um método de deposição física via fase de vapor (Physical Vapour Deposition, PVD). Neste processo, átomos do material são arrancados da superfície de um alvo por íons de alta energia gerados por um plasma contido em uma câmara de vácuo [7].

As principais vantagens do processo de sputtering são [3]: produção de filmes de praticamente qualquer material, inclusive isolantes e refratários; deposição de filmes a partir de alvos compostos, com a conservação da estequiometria; excelente aderência dos filmes depositados; produção de filmes com alta densidade; homogeneidade de espessura da camada depositada.

Os equipamentos de sputtering podem apresentar diferentes formas construtivas de acordo com o tipo de aplicação e o material do alvo. Comercialmente é possível encontrar inúmeros modelos de sputtering, porém os mais utilizados são: sputtering convencional, magnetron sputtering e sputtering de radio freqüência (RF). Os dois primeiros tipos são indicados para produção de filmes a partir de alvos metálicos e condutores enquanto o último é para alvos isolantes ou materiais na forma de óxidos [3]. A combinação do tipo RF com o magnetron resulta no equipamento denominado de RF Magnetron Sputtering que 
é o mais indicado para a produção de filmes finos a partir de alvos de compostos por óxidos, nitretos ou carbetos [3]. $\mathrm{O}$ princípio de funcionamento do sputtering convencional é a base construtiva para os demais equipamentos de deposição deste tipo. O sistema é apresentado na Fig. 2 e consiste de uma câmara de vácuo com uma entrada de gás e dois eletrodos onde é aplicada uma diferença de potencial. $\mathrm{O}$ alvo é colocado no cátodo e o substrato onde se deseja depositar o filme é colocado no ânodo. Ambos os eletrodos são devidamente conectados a uma fonte de alta tensão. Um gás inerte como o argônio, por exemplo, é introduzido na câmara com uma determinada vazão, mantendo-se uma pressão máxima em torno de $100 \mathrm{mTorr}(1,3 \mathrm{~Pa})$. A partir deste momento, é aplicada uma tensão entre os eletrodos para gerar uma descarga elétrica de tal forma que ocorra a produção de íons positivos do gás. Esses, ao adquirirem carga positiva são conseqüentemente acelerados contra 0 alvo negativo. Com a estabilização da descarga e a produção de íons positivos do gás ocorre a formação de uma descarga luminescente chamada de plasma [3].

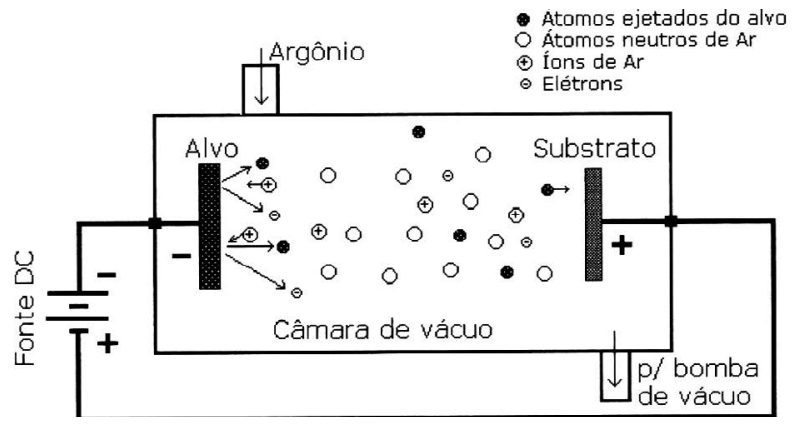

Figura 2: Esquema de um sputtering convencional. Fonte: [3].

[Figure 2: Schematic of a conventional sputtering. Source: [3].]

\section{Dip coating}

Dip coating é uma técnica utilizada para aplicação de filmes finos a partir de precursores em fase líquida (Fig. 3). Nesse processo, o substrato a ser revestido é imerso perpendicularmente dentro da solução contendo o precursor e depois retirada com uma velocidade bem definida sob temperatura controlada e condições atmosféricas [16]. A inserção e retirada do substrato na solução deve ser realizada de forma constante e sem nenhum tipo de vibração ou interferência externa, de modo a garantir a deposição de um filme homogêneo. O tempo de permanência do substrato na solução anteriormente à sua retirada também é um fator de controle importante. Isto significa que para se obter filmes de qualidade, além das características do substrato e da solução precursora (solvente, concentração, viscosidade, tipo de precursor), é necessária a utilização de um equipamento que promova a inserção e a retirada do substrato com alta estabilidade, com controle fino da velocidade e livre de vibrações [9]. A espessura do revestimento é principalmente definida pela velocidade de retirada, pelo teor de sólidos e viscosidade do líquido.

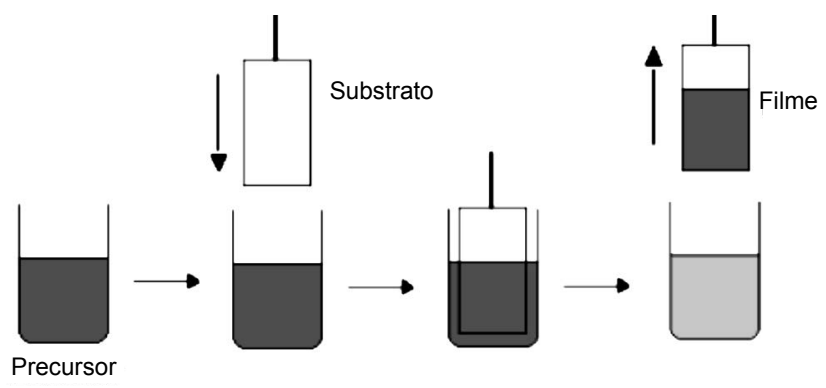

Figura 3: Representação esquemática do processo de obtenção de filmes finos pelo processo de dip coating. Fonte:[17].

[Figure 3: Schematic representation of the process for obtaining thin films by dip coating process. Source: [17].]

\section{Spin coating}

O método de spin coating (Fig. 4) consiste em depositar gotas da solução precursora inicial sobre um substrato que apresenta um movimento de rotação [17]. Assim, o substrato gira em torno de um eixo que deve ser perpendicular à área de revestimento [16]. A evaporação dos solventes mais voláteis no momento da deposição permite acelerar os processos de hidrólise e condensação iniciados com o contato com a umidade do ar ambiente [17].

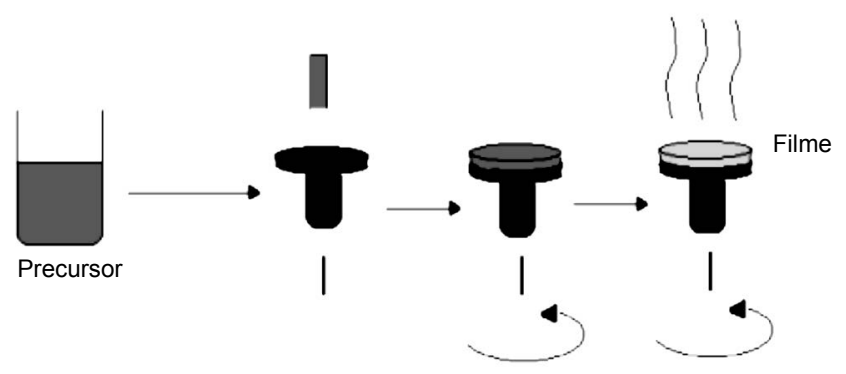

Figura 4: Representação esquemática do processo de obtenção de filmes finos por spin coating. Fonte:[17].

[Figure 4: Schematic representation of the process for obtaining thin films by spin coating. Source: [17].]

\section{Obtenção de filmes espessos - Serigrafia plana}

A serigrafia plana é uma técnica muito utilizada industrialmente, podendo ser executada de forma artesanal, por meio de instrumentos rudimentares ou de forma automática recorrendo ao uso de tecnologias de última geração. É uma técnica de impressão muito versátil, pois permite imprimir sobre superfícies planas, independentemente do material (papel, plástico, borracha, madeira, vidro, cerâmico ou outros), com tamanhos ou espessuras variáveis de substrato (Fig. 5) [14, 18, 19].

$\mathrm{O}$ equipamento necessário é um quadro serigráfico com tela, espátula e tinta serigráfica. O processo consiste na transferência da tinta serigráfica, da parte superior do quadro para a superfície a serigrafar, através da aplicação de pressão pela passagem da espátula $[14,18,19]$. O quadro serigráfico é uma armação, que pode ser de madeira, ferro ou alumínio, quadrada ou retangular, que sustenta a tela ou malha 


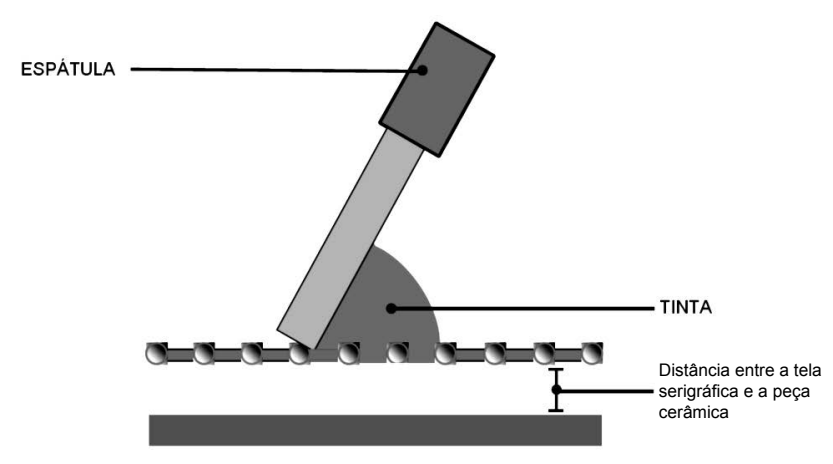

Figura 5: Esquema de aplicação por serigrafia plana. Fonte:Adaptado [19.]

[Figure 5: Outline of the application by screen printing. Source: Adapted from [19].]

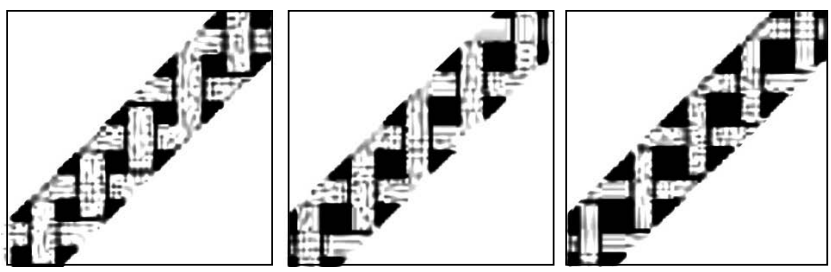

Figura 6: Representação de malhas com mesmo número de fios e diâmetros diferentes. Fonte: [14].

[Figure 6: Representation of meshes with the same number of wires and different diameters. Source: [14].]

serigráfica. $\mathrm{O}$ aro tem de ser suficientemente rígido para que não ocorram deformações quando é aplicada a pressão na tela para a passagem da tinta. A seleção do quadro serigráfico é feita de acordo com as necessidades do sistema onde será realizada a impressão, dependendo do tipo de máquina, do formato, da velocidade de impressão, entre outros [14, 18, 19]. A tela ou malha serigráfica pode ser de nylon ou poliéster e tem de apresentar uma textura regular, elevada resistência mecânica e química. As telas são caracterizadas por um número a que corresponde o número de fios por centímetro linear. De forma geral, quanto menor for este número, menor será a definição obtida e mais aberta será a malha; pelo contrário, a um maior número de fios corresponde um desenho mais definido e uma menor passagem de tinta. O diâmetro do fio da tela (Fig. 6) é um parâmetro que também tem influência na definição do desenho obtido e na quantidade de tinta que passa para o material. Quanto maior for o diâmetro do fio, para o mesmo número de fios, menor a abertura da malha, passando menos tinta e maior será a sua resistência mecânica $[14,19]$.

Quanto ao diâmetro dos fios, existem três tipos [14]: fio fino proporciona uma maior definição do desenho, mas apresenta menor resistência mecânica; fio médio é o mais utilizado, pois alia uma boa definição a uma resistência mecânica aceitável; fio grosso, cuja definição do desenho obtido é menor, mas exibe uma elevada resistência mecânica. A espátula é o acessório utilizado para fazer passar a tinta, da tela serigráfica para a superfície a imprimir, através da aplicação de pressão. A espátula tem um cabo (de madeira ou de metal) e uma lâmina, de borracha ou de poliuretano. Dependendo do tipo de impressão que se pretende, a lâmina pode apresentar diferentes cortes, durezas e tamanhos [14]. A tinta serigráfica é determinante para a qualidade do trabalho de impressão. A sua composição e características variam com o material a serigrafar, o tipo de tela e de impressão utilizada $[14,18,19]$.

\section{Pulverização}

A pulverização, também designada por aerografia, é uma técnica de deposição que utiliza um instrumento designado de aerógrafo $[14,18]$. A suspensão é colocada num recipiente próprio ligado ao aerógrafo, que pode ser fixo ou móvel. A sua localização determina se a alimentação da tinta é efetuada por sucção, caso se localize abaixo do bico, ou por gravidade, caso se localize acima do bico. Na Fig. 7, pode-se observar o aerógrafo de ação simples em que a tinta é alimentada por gravidade [14]. A característica principal da aplicação é obtida com a pulverização a alta velocidade da suspensão, com o objetivo de obter um gotejamento muito fino. A suspensão deve ter alto limite plástico com baixa viscosidade [18].

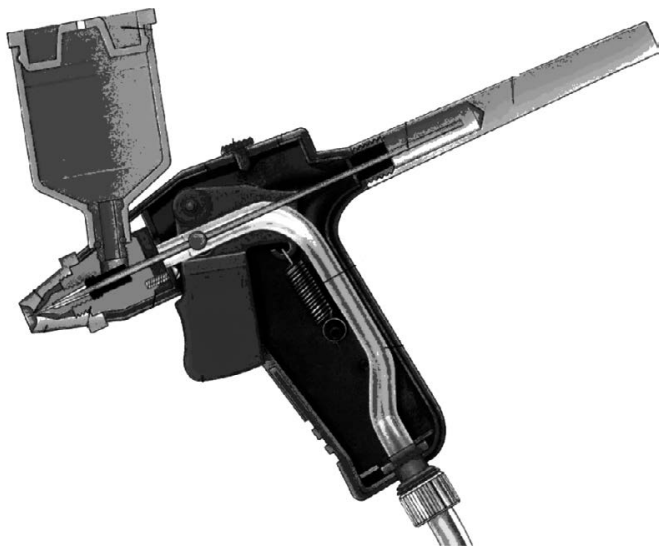

Figura 7: Aerógrafo com a alimentação da tinta por gravidade. Fonte: [14].

[Figure 7: Airbrush feeding the ink by gravity. Source: [14].]

Os aerógrafos podem ainda ser classificados como de mistura interna ou externa. No primeiro caso, a mistura de ar e tinta é feita no interior da pistola, produzindo um jato muito suave, sendo muito utilizado em acabamentos finos. No caso do aerógrafo de mistura externa, a mistura de ar e tinta é feita no exterior da pistola e o jato produzido é mais grosseiro. Esse último tipo de mistura é normalmente utilizado quando se pretende pulverizar grandes áreas e superfícies [14]. A qualidade da superfície obtida por pulverização é influenciada pelas características da suspensão, em particular a viscosidade e a densidade, as quais devem ser ajustadas de modo a obter uma camada com a quantidade pretendida e com uma superfície homogênea $[14,18]$.

\section{Incavografia}

A incavografia (rotocolor) [20] tem sido uma tecnologia muito utilizada no setor cerâmico para a decoração de revestimentos cerâmicos [21]. A técnica consiste em decorar 


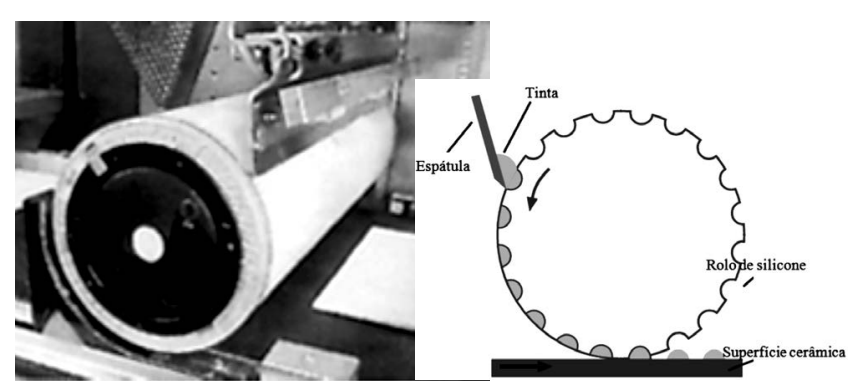

Figura 8: Sistema de decoração por rolo de silicone. Fonte: [22]. [Figure 8: Decoration system by silicone roller. Soruce: [22].]

as cerâmicas através de rolos nos quais se grava um desenho em forma de pontos (alvéolos) [22] (Fig. 8), seja por laser (tecnologia rotocolor), ou por luz ultravioleta (tecnologia digital roller - Cretaprint). Os alvéolos ou pontos gravados são as cavidades que armazenam a tinta para depois transmiti-la à cerâmica. A tinta é transferida a superfície cerâmica mediante três princípios: o fenômeno físico pelo qual se transmite a tinta é o da capilaridade; ocorre o contato do rolo impressor com a cerâmica; o esmalte absorve a tinta do interior dos alvéolos [21].

\section{Impressão a jato de tinta}

A impressão a jato de tinta (inkjet) é uma tecnologia de decoração de deposição de tinta sem contato. A tinta em forma de pequenas gotas é lançada de um dos cabeçotes injetores sobre o suporte que se vai decorar. Em relação ao mecanismo de aporte de tinta é possível distinguir dois métodos: o jato de tinta contínuo e o jato de tinta sob demanda. A informação digitalizada em um computador é usada para dirigir a tinta através de diminutos canais e assim formar padrões alfanuméricos ou de pontos. A tinta, transportada através destes canais, é transferida ao suporte, dando lugar à imagem impressa. Isso evita o uso de agentes intermediários que requerem um contato íntimo (pressão) com o suporte para poder realizar a transferência da tinta [23].

\section{Tratamentos térmicos}

A transformação da fase anatase em rutilo é termodinamicamente favorável em temperaturas acima de $400{ }^{\circ} \mathrm{C}$ [3]. Essa transformação de fase e tamanho dos cristais é representada na Fig. 9 através dos difratogramas dos pós calcinados de titânia a diferentes temperaturas durante $1 \mathrm{~h}$.

A evolução das fases apresentadas nos difratogramas pode variar em função do tamanho inicial das partículas da titânia e atmosfera de queima, além de outros parâmetros de processamento. A avaliação dos difratogramas ilustra os resultados de pesquisas pontuais e são utilizadas como exemplos: abaixo de $250{ }^{\circ} \mathrm{C}$ o $\mathrm{TiO}_{2}$ existe em seu estado amorfo e após aquecimento as intensidades de pico de anatase aumentam significativamente; abaixo de $600^{\circ} \mathrm{C}$ podese verificar apenas a fase anatase; acima de $600^{\circ} \mathrm{C}$ as fases anatase e rutilo coexistem; a $750^{\circ} \mathrm{C}$ o cristal anatase apresenta

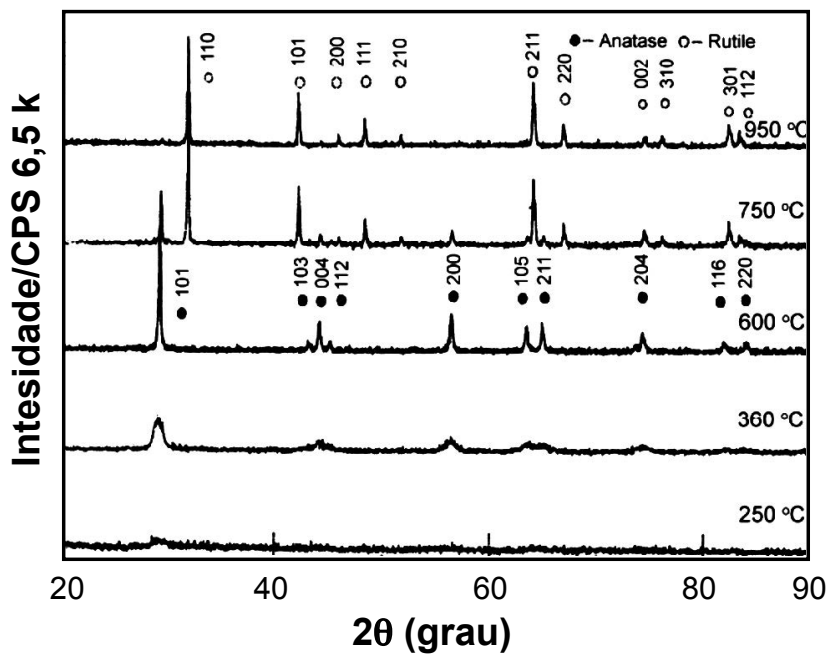

Figura 9: Difratogramas de raios X dos pós de titânia submetidos a diferentes temperaturas por $1 \mathrm{~h}$. Fonte: [24].

[Figure 9: X-ray diffraction patterns of the powders of titania submitted to different temperatures for $1 \mathrm{~h}$. Source: [24].]

em média cerca de $48 \mathrm{~nm}$ e o de rutilo aproximadamente 70 $\mathrm{nm}$; a $900{ }^{\circ} \mathrm{C}$ a fase anatase é totalmente transformada para rutilo com um tamanho de cristal inferior a $100 \mathrm{~nm}$; quando calcinados a $950{ }^{\circ} \mathrm{C}$ o tamanho dos cristais de rutilo aumenta para $115 \mathrm{~nm}$; nessa análise, $950{ }^{\circ} \mathrm{C}$ é temperatura final de transformação, onde há $100 \%$ de fase rutilo [24].

Em todas as temperaturas e pressões, rutilo é comprovadamente a fase estável de $\mathrm{TiO}_{2}$ (Fig. 10). Isto foi confirmado também em estudos termodinâmicos, pelos quais seriam necessárias pressões negativas para anatase ser mais estável que rutilo [25].

A temperatura em que a transição $A \rightarrow R$ é observada depende de uma série de parâmetros e por isso há na literatura intervalos de temperaturas diferentes. Considerase que pós finos de anatase de alta pureza transformam-se a temperaturas na faixa de 600 a $700{ }^{\circ} \mathrm{C}$ [25]. A transformação da fase $\mathrm{A} \rightarrow \mathrm{R}$ termodinamicamente estável não tem uma temperatura de transformação definida. A temperatura de formação da fase anatase é altamente dependente de numerosos parâmetros relacionados com natureza do material, tratamento térmico e método de medição [25]: tempo; temperatura; atmosfera; composição química intrínseca (pureza das matérias-primas); contaminação extrínseca (de processamento); homogeneidade química (por exemplo, a segregação); homogeneidade microestrutural (por exemplo, precipita contorno de grão); homogeneidade térmica durante o aquecimento (por exemplo, resultantes de tamanho da amostra e forma); fase mineralógica; distribuição de tamanho de partícula; distribuição de tamanho de aglomerado; morfologia dos grãos; morfologia dos aglomerados. Outra questão importante e que deve ser levada em consideração é o tamanho do cristalito formado com o aumento da temperatura. Anatase é geralmente mais estável quando os cristais são menores que $30 \mathrm{~nm}$, enquanto rutilo é a fase mais favorecida em tamanho cristal maior. A transformação de fase $\mathrm{A} \rightarrow \mathrm{R}$ é relatada como um processo de nucleação e crescimento [26] e pode ser verificado que 

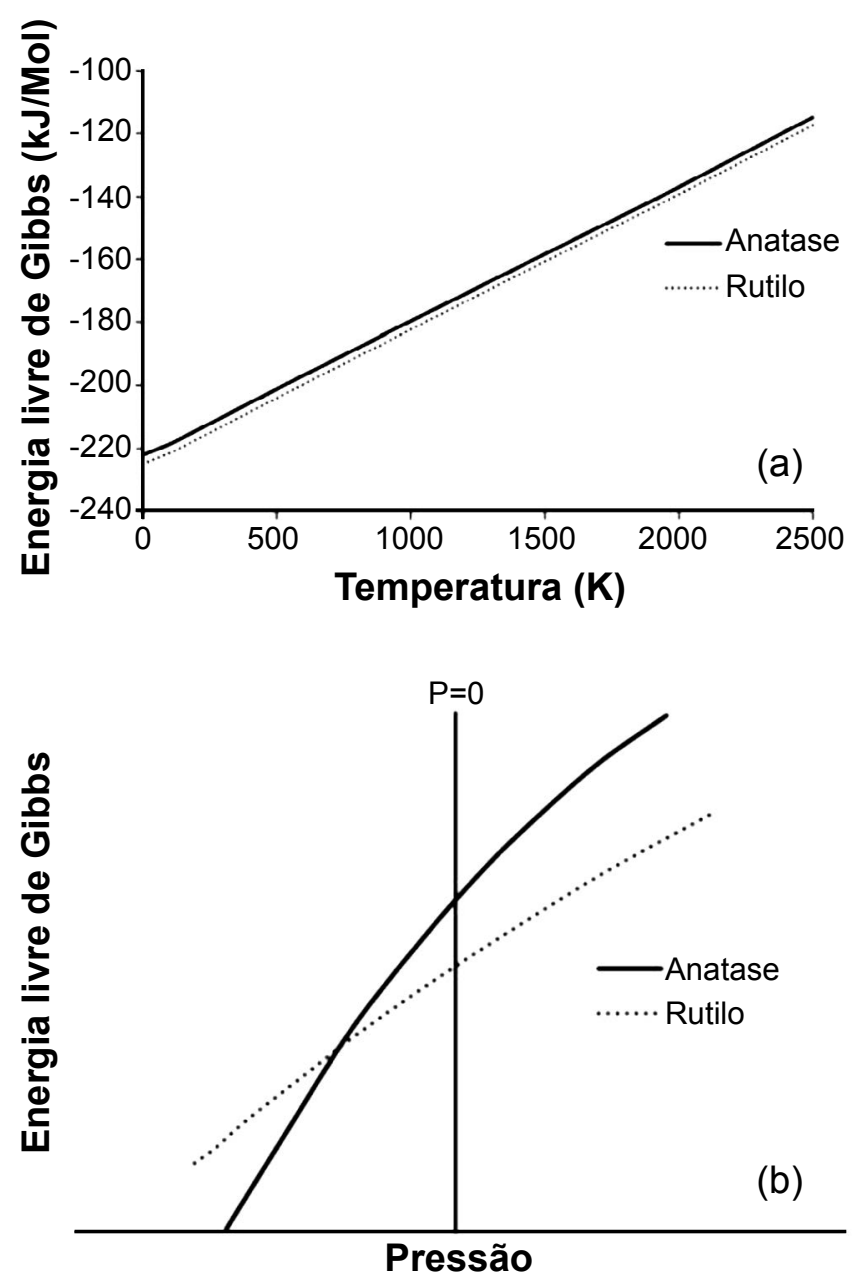

Figura 10: (a) Energia de Gibbs de anatase e rutilo versus temperatura, (b) Energia de Gibbs versus pressão (temperatura ambiente). Fonte: [25].

[Figure 10: (a) Gibbs energy of anatase and rutile versus temperature, (b) Gibbs energy versus pressure (room temperature). Source: [25]].

as partículas atingem um tamanho crítico por um processo de amadurecimento, pelo qual as partículas menores são consumidas por difusão atômica [27]. Alguns estudos sugerem que o tamanho crítico do cristalito de anatase na transformação a rutilo esteja na faixa de 30 a $40 \mathrm{~nm}$ [26]. Adições de dopantes ( $\mathrm{Si}, \mathrm{Al}$ e $\mathrm{Zr}$ ) fazem com que o tamanho crítico pode chegar a $45 \mathrm{~nm}$, porém a utilização de dopantes não altera esta característica [27]. Contudo, o tratamento térmico contribui para crescimento do cristal, transformando anatase em rutilo, sendo sempre necessário investigar como a transição de fase é influenciada com o aumento temperatura [26].

O efeito de um dopante/estabilizante é inibir o crescimento do cristalito, de modo que a transformação não seja termodinamicamente favorecida. Ao aumentar a temperatura, o cristalito da anatase cresce até um limite e a estrutura permanece inalterada. As superfícies sofrem interações que podem retardar a transformação assim como o crescimento. Como as transformações de fase em nanopartículas podem ser iniciadas através da nucleação nas interfaces, os dopantes de superfície podem estabilizar as fases, alterando a energia de ativação da transformação. $O$ fator principal nessas estruturas dopadas é que o "estabilizante" diminui a energia interfacial. A teoria relata que as superfícies que contêm “contaminantes" são eficientes na estabilização, fato relevante para a manutenção das propriedades de catalisadores em nanoescala e que operam em altas temperaturas [28].

\section{CONSIDERAÇÕES FINAIS}

Esta revisão apresentou parâmetros de processo que podem influenciar na eficiência fotocatalítica de superfícies cerâmicas. $\mathrm{O}$ primeiro parâmetro se refere à influência do substrato. Nesse caso, superfícies ásperas apresentam maior percentual de degradação fotocatalítica em relação a superfícies lisas, que se justifica pelo aumento da área superficial disponível para decomposição. $\mathrm{O}$ segundo parâmetro corresponde aos métodos de deposição de dióxido de titânio em superfícies cerâmicas. Destacam-se as aplicações de filmes finos em substratos cerâmicos como magnetron sputtering, dip coating, spin coating. Para os filmes espessos, as técnicas de aplicação mais utilizadas são serigrafia plana, aerografia, incavografia e impressão digital. O último parâmetro relaciona-se ao tratamento térmico. Ao se aumentar à temperatura, a taxa de transformação da fase anatase para rutilo aumenta significativamente. A faixa de transformação de anatase para rutilo depende de inúmeros variáveis, relacionadas a características do pó e de condições ambientais durante o tratamento térmico.

\section{AGRADECIMENTOS}

Os autores agradecem ao Conselho Nacional de Desenvolvimento Científico e Tecnológico (CNPq, Brasil) e à Fundação para a Ciência e a Tecnologia (FCT, Portugal) pelo auxilio financeiro à pesquisa.

\section{REFERÊNCIAS}

[1] A. Fujishima, T. N. Rao, D. A. Tryk, J. Photochem. Photobiol. C: Photochem. Rev. 1 (2000) 1.

[2] D. P. Macwan, P. N. Dave, S. Chaturvedi, J. Mater. Sci. 46 (2011) 3669.

[3] A. O. Silva, "Estudo da Obtenção de Filmes de Anatásio Utilizando RF-magnetron Sputtering”, UFSC (2000).

[4] J. Määttä, M. Piispanen, H. R. Kymäläinen, A. UusiRauva, K. R. Hurme, S. Areva, A. M. Sjöberg, L. Hupa, J. Eur. Ceram. Soc. 27 (2007) 4569.

[5] Z. Zeng, C. Peng, Y. Hong, Y. Lu, J. Wu, J. Am. Ceram. Soc. 93 (2010) 2948.

[6] D. S. Tsoukleris, A. I. Kontos, P. Aloupogiannis, P. Falaras, Catalysis Today 124 (2007) 110.

[7] S. Pascali, "Obtenção e Caracterização de Filmes de $\mathrm{TiO}_{2}$ Depositados sobre Cerâmica de Revestimento via Magnetron Sputtering DC", UFSC (2007).

[8] M. H. Habibi, N. Talebian, J.-H. Choi, Dyes Pigments 
73 (2007) 103.

[9] A. R. M. Oliveira, A. J. G. Zarbin, Química Nova 28 (2005) 141.

[10] V. S. Smitha, K. A. Manjumol, K. V. Baiju, S. Ghosh, P. Perumal, K.G.K. Warrier, J. Sol-Gel Sci. Technol. 54 (2010) 203.

[11] B. K. Kaleji, R. Sarraf-Mamoory, S. Sanjabi, Reaction Kinetics, Mechanisms Catalysis 103 (2011) 289.

[12] E. Arpaç, F. Sayilkan, M. Asiltürk, P. Tatar, N. Kiraz, H. Sayilkan, J. Hazardous Mater. 140 (2007) 69.

[13] E. B. M. Rego, "Fotodegradação de Soluções de Laranja II e Efluentes da Indústria Têxtil por Camadas de $\mathrm{TiO}_{2}$ e $\mathrm{ZnO}$ Serigrafadas em Peças Cerâmicas", Universidade de Aveiro, Portugal (2008).

[14] R. M. R. Pires, “Optimização Industrial de Revestimentos Cerâmicos com Propriedades Fotocatalíticas”, Universidade de Aveiro, Portugal (2010).

[15] M. Raimondo, G. Guarini, C. Zanelli, F. Marani, L. Fossa, M. Dondi, Ceram. Int. 38 (2012) 4685.

[16] H. Schmidt, M. Mennig, The Sol-Gel Gateway (2000) 1.

[17] E. J. Nassar, K. J. Ciuffi, R. R. Gonçalves, Y. Messaddeq, S. J. L. Ribeiro, Química Nova 26 (2003) 674.

[18] ACIMAC, in "Glazing \& Decoration of Ceramic Tiles Smaltatura e Decorazione delle Piastrelle Ceramiche", Italy (2000) pp. 83-88.

[19] V. Sanz, E. Sánchez, E.B.M. Tirado, Ceram. Ind. 4 (1999) 19.

[20] M. J. A. Torres, A. Boix, F. Chillarón, S. Peiró, J. Gargori, Ceram. Ind. (2004) 13.

[21] F. Perez, Ceram. Ind. 12 (2007) 1.

[22] J. M. Campos, P. Corma, F. Lucas, S. Pasquetto, Ceram. Ind. 7 (2002) 18.

[23] Y. Reig, V. Lázaro, A. Mateu, C. Feliu, Ceram. Ind. 17 (2012) 20.
[24] Y. Shao, D. Tang, J. Sun, Y. Lee, W. Xiong, China Particuology 2 (2004) 119.

[25] D. A. H. Hanaor, C. C. Sorrell, J. Mater. Sci. 46 (2011) 855.

[26] L. Andronic, D. Andrasi, A. Enesca, M. Visa, A. Duta, J. Sol-Gel Sci. Technol. 58 (2010) 201.

[27] D. J. Reidy, J. D. Holmes, M. A. Morris, J. Eur. Ceram. Soc. 26 (2006) 1527.

[28] B. Chen, H. Zhang, B. Gilbert, J. Banfield, Phys. Rev. Lett. 98 (2007) 106103.

[29] M. Hofer, D. Penner, J. Eur. Ceram. Soc. 31 (2011) 2887.

[30] O. Ruiz, F. Sanmiguel, C. Gargori, F. Galindo, G. Monrós, Ceram. Ind. (2009) 7.

[31] B. Huber, A. Brodyanski, M. Scheib, A. Orendorz, C. Ziegler, H. Gnaser, Thin Solid Films 472 (2005) 114.

[32] M. Fassier, N. Chouard, C. S. Peyratout, D. S. Smith, H. Riegler, D. G. Kurth, C. Ducroquetz, M. A. Bruneaux, J. Eur. Ceram. Soc. 29 (2009) 565.

[33] M. Piispanen, J. Määttä, S. Areva, A. M. Sjöberg, M. Hupa, L. Hupa, J. Eur. Ceram. Soc. 29 (2009) 1855.

[34] M. P. Seabra, R. R. Pires, J. A. Labrincha, Chem. Eng. J. 171 (2011) 692.

[35] E. Rego, J. Marto, P. S. Marcos, J. A. Labrincha, Appl. Catalysis A: General 355 (2009) 109.

[36] M. C. Hidalgo, S. Sakthivel, D. Bahnemann, Appl. Catalysis A: General 277 (2004) 183.

[37] C. Guillard, H. Lachheb, A. Houas, M. Ksibi, E. Elaloui, J. Herrmann, J. Photochem. Photobiol. A: Chem. 158 (2003) 27.

[38] G. Li, L. Chen, M. E. Graham, K. A. Gray, J. Molecular Catalysis A: Chem. 275 (2007) 30.

[39] J. B. Naceur, M. Gaidi, F. Bousbih, R. Mechiakh, R. Chtourou, Current Appl. Phys. 12 (2012) 422.

(Rec. 13/03/2013, Rev. 28/05/2013, Ac. 12/07/2013) 